\title{
Studies of factors affecting stability and efficiency of anion exchanger
}

\author{
Nigora Mukhtarova ${ }^{1}$, Bakhodir Aliev ${ }^{1}$, Sadritdin Turabdzhanov ${ }^{1}$, and Latofat \\ Rakhimova ${ }^{1, *}$ \\ ${ }^{1}$ Tashkent State Technical University named after Islam Karimov, Ecology and protection of \\ environment Department, 100095, University 2 street, Tashkent, Uzbekistan
}

\begin{abstract}
Various industries such as mining and the chemical industry are one of the most used ion exchange processes for water and wastewater treatment. The first section of this work presents the mechanism of the polycondensation reaction to obtain the polymer matrix of anion exchanger. Elemental analytical data conformed that anion exchanger holds $34,99 \%$ of nitrogen atoms and $44,47 \%$ oxygen atoms in the structure. In addition to the synthesis of the anion exchanger, physicochemical factors have a significant effect. The temperature of reactions for a certain time using a Lewis catalyst, the choice of the optimal solvent for improving swelling capacity of the starting monomers, due to their advantages as effective materials at a low price, are described in the second section. The information in the last section of the paper is devoted to the sorption properties and the ion-exchange processes in where the obtained anion exchanger was studied and used.
\end{abstract}

\section{Synthesis of anion exchanger}

The synthesis of organic polymers, called ion-exchange polymers, is rightfully considered one of the largest achievements of chemical science. An amazing variety of properties of these polymers, and especially their favorable performance characteristics, ensured the successful use of new sorbents for solving a wide range of scientific and practical problems - from virtuosic analytical divisions and preparative syntheses of organic substances to metal extraction from ores and purification of huge volumes of natural water from dissolved electrolyte impurities [1]. Ion exchanger production was radically altered by the discovery of

\footnotetext{
* Corresponding author: latofat.2011@mail.ru
} 
synthetic resin exchangers by B. A. Adams and E. L. Holmes in 1935. They used a condensation polymerization reaction to create a granular material able to be used in columns and until very recently the majority of ion exchange has been carried out on resin-based materials [2]. Styrene/divinylbenzene copolymers, polymethacrylate, and other polyvinyl resins are common as support materials in the manufacturing process for polymer-based anion exchangers [3]. Searching of cheap and affordable materials or monomers is relevant for the production of anion exchangers. We used furfural as a cross-linked agent and diphenylamine as a carrier of ionogenic groups for obtaining new type of anion exchanger [4].

\subsection{Mechanism of reaction of polycondensation}

Mechanism of the reaction is based on the electrophilic substitution of a hydrogen atom and orto- position of the benzene ring in the presence of a catalyst. Most of the researchers used $\mathrm{ZnCl}_{2}$ as the Lewis acid catalyst [5], in which the central metal atom contains free orbital cells in the structure and is thus capable of acting as an electron acceptor [6].

Formation of a strongly polarized active donor-acceptor complex with the participation of furfural and catalyst molecules is observed according to the scheme:

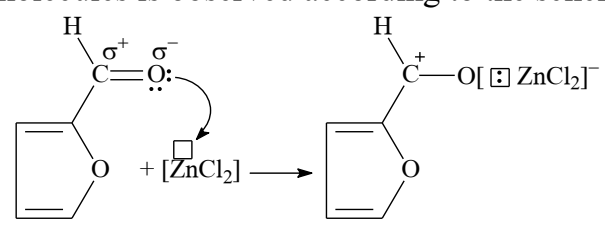

At the next stage, the resulting complex attacks the diphenylamine molecule:
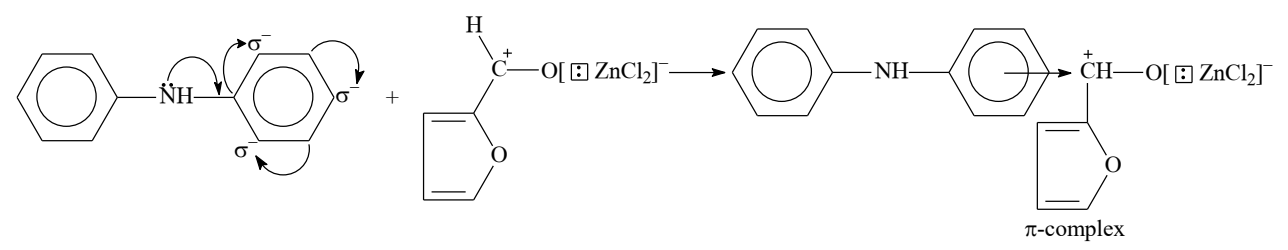

As a result, a $\pi$-complex is formed with the participation of the benzene ring and the strongly polarized active complex. This $\pi$-complex is not stable and it turns into an s-complex. An s complex is a cation lacking an aromatic structure.

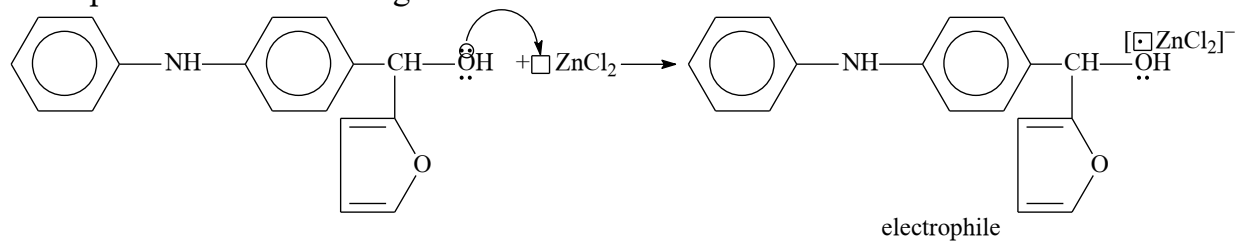


A stronger electrophilic, acting as an active center, formed according to the following scheme:

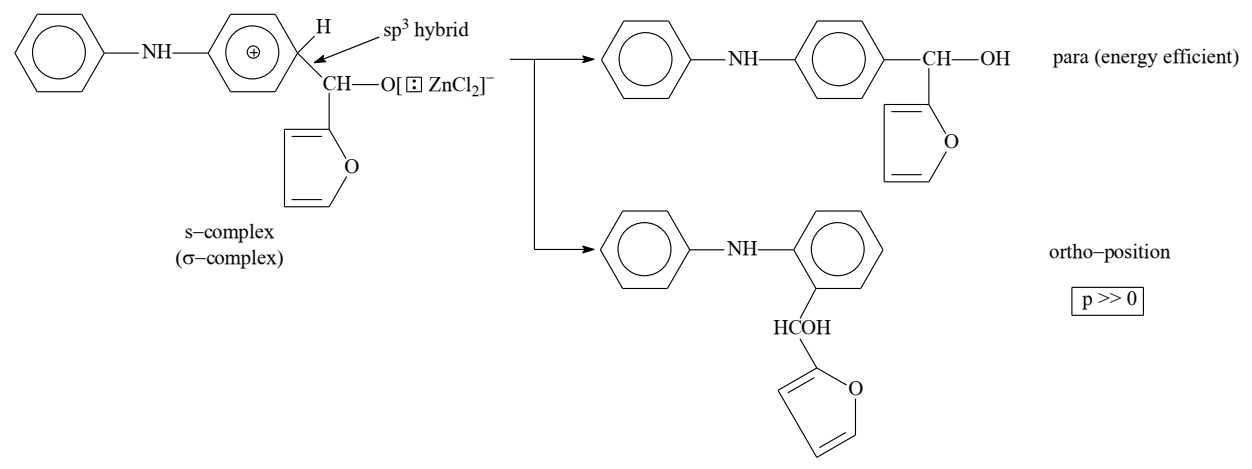

The next stage is chain growth:

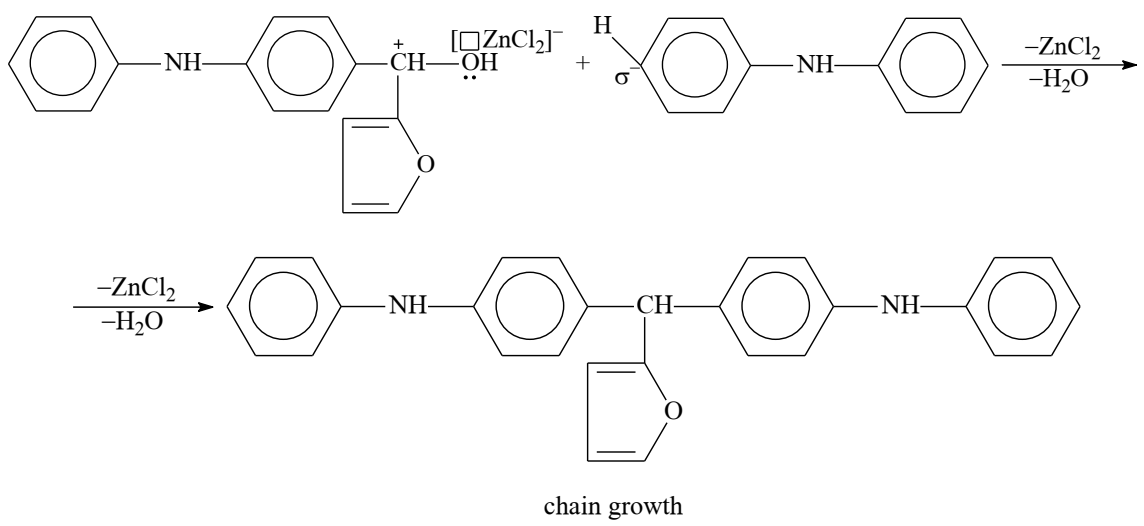

With four p-electrons delocalized (in other words, distributed) in the sphere of action of the nuclei of five carbon atoms. The sixth carbon atom changes the hybrid state of its electron shell from $\mathrm{sp}^{2}-$ to $\mathrm{sp}^{3}$-, leaves the plane of the ring and acquires tetrahedral symmetry. Both substituents - hydrogen atoms and a catalyst-containing fragment — are located in a plane perpendicular to the plane of the ring. At the next stage of the reaction, the proton is detached from the s-complex, the aromatic system is restored, since the pair of electrons missing from the aromatic sextet is returned to the benzene nucleus. This process is accompanied by the formation of two more stable but active intermediate isomeric compounds capable of forming active centers - stronger electrophiles. It should be noted that due to steric factors, the proportion of the $\mathrm{p}$-isomer prevails over the o-isomer.

Finally, chain-growing process became constantly after we can obtain structure formula of anion exchanger. Two aromatic rings between amino grope and heterocyclic ring of 
furfural gives anion exchanger mechanical durability properties. Elemental analytical data conformed that anion exchanger holds $34,99 \%$ of nitrogen atoms $(\mathrm{N})$ in the structure.

\section{Studies of effecting factors}

Anion exchanger was synthesized from diphenylamine (DPA) by condensation reaction with furfural in the presence of dimethylformamide. Ion exchanger synthesized using various ratios of the initial reactants in order 1: 1, 1:1.25. The reaction was carried out for 6 hours at $100^{\circ} \mathrm{C}$. Furfural during of interacting with DPA playing role of crosslinking agent in a solvent of DMF proceeds with the formation of a three-dimensional structure. The properties of the obtained anion exchanger depends on the degree of crosslinking, swelling and exchange capacity of anion exchanger increases with a decrease of the amount of furfural in the reaction mixture, however, an increase in the concentration of furfural increases the degree of polymer crosslinking, thereby increasing the mechanical strength of the ion exchanger. Based on the foregoing, the optimal ratio of DPA to furfural was 1: 1.25.

\subsubsection{Solution phase and catalyst effects}

For a uniform course of the interaction between DPA and furfural, the reaction was carried out in a solvent environment. The nature of the solvent and the degree of solubility of the initial monomers affects properties of obtained anion exchanger. Ethyl, n-butyl alcohols and dimethylformamide used as a solvent. Each obtained anion exchanger tested with $0.1 \mathrm{n}$ solution $\mathrm{HCl}$ by exchange capacity of according to used solvent. Using by ethanol ion exchange capacity was 1.2-1.3 meq / g, with n-butyl ethanol 0.8-1.2 meq / g and for DMF equal 2.2-2.5 $\mathrm{meq} / \mathrm{g}$.

Increasing in the amount of $\mathrm{ZnCl}_{2}$ catalyst accelerates the polycondensation reaction and results in a high crosslink density anion exchanger with low swelling capacity in water. Experiments showed that the most optimal concentration of $\mathrm{ZnCl}_{2}$ catalyst is $5-7 \%$ by weight of furfural. This ensures a uniform reaction, which leads to the synthesis of anion exchanger with the required indicators of physical and chemical properties. Mechanical stability of anion exchanger $96 \%$ using by DMF as a solvent.

\subsubsection{Temperature and time}

Usually, the temperature of polycondensation in solution is in the range $20-250{ }^{\circ} \mathrm{C}$. In the course of solution polycondensation the polymer can form thermodynamically unstable (metastable) solutions [7]. In our case, the polycondensation reaction time at a temperature of $90^{\circ} \mathrm{C}$ corresponds to -7 hours (Fig.1). 


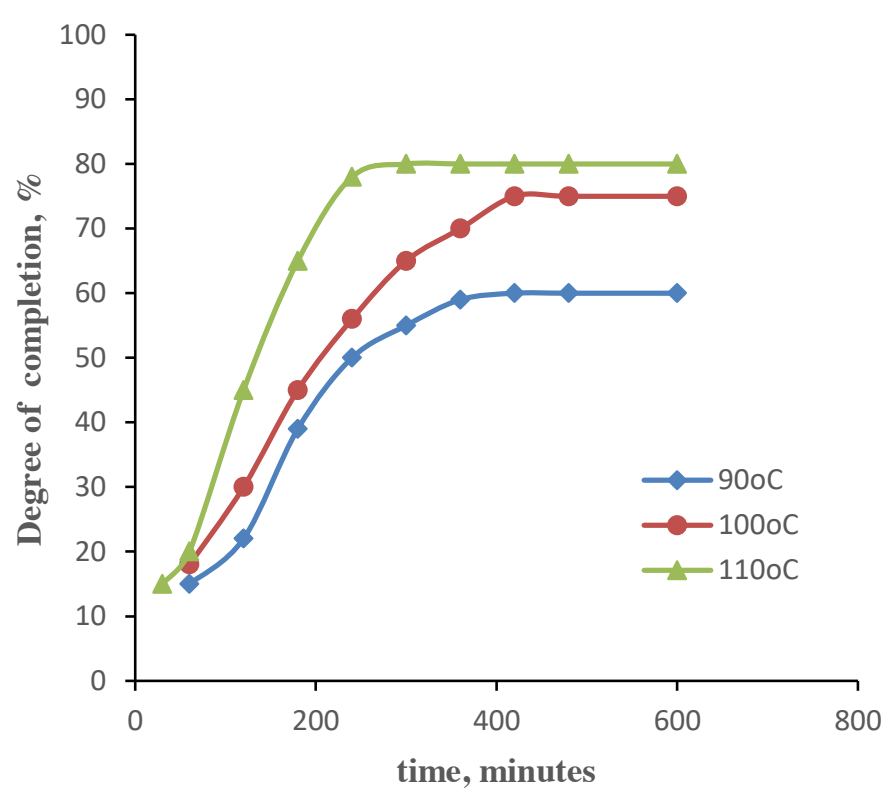

Fig.1. Dependence of the degree of completion (\%) of the polycondensation reaction on the duration of the reaction at the various temperatures.

Therefore, the optimum temperature for the polycondensation of DPA with furfural was taken to be $100{ }^{\circ} \mathrm{C}$ during the time of the process 6 hours, when the reaction proceeds uniformly.

The swelling capacity of synthesized anion exchanger swollen in water in the $\mathrm{OH}$ form is $2.5 \mathrm{ml} / \mathrm{g}$. It is interesting that swelling capacity plays an important role for anion exchangers since tendency of an ion exchanger to expand or contract depending on the counterions associated with it [8].

\section{3 lon exchange capacity (IEC)}

Anion exchange is the exchange of anions present in water $\left(\mathrm{SO}_{4}^{2-}, \mathrm{HCO}_{3}^{-}, \mathrm{Cl}^{-}\right.$etc. $)$for hydroxide ions $\left(\mathrm{OH}^{-}\right)$. This exchange, following cation exchange, completely demineralizes water when carried to completion. An example of typical anion exchange reactions is shown below.

Operation: $2 \mathrm{R}+\mathrm{OH}^{-}+\mathrm{H}_{2} \mathrm{SO}_{4}$

$$
\begin{aligned}
& \mathrm{R}+2 \mathrm{SO}_{4}^{2-}+2 \mathrm{H}_{2} \mathrm{O} \\
& \mathrm{R}+\mathrm{OH}^{-}+\mathrm{HCl}^{-} \\
& \mathrm{R}+\mathrm{Cl}^{-}+\mathrm{H}_{2} \mathrm{O}
\end{aligned}
$$


Regeneration: $\mathrm{R}+\mathrm{Cl}^{-}+\mathrm{NaOH} ; \mathrm{R}+\mathrm{OH}^{-} \mathrm{NaCl}[9]$.

Obtained ion exchanger has a sorption capacity by the concentration of solutions $0.1 \mathrm{~N}$ acid residues in the following order: $\mathrm{HCl}-2.2-2.5 \mathrm{meq} / \mathrm{g}, \mathrm{H}_{2} \mathrm{SO}_{4}-3.8-3.5 \mathrm{meq} / \mathrm{g}, \mathrm{HNO}_{3}-2.3-$ $2.4 \mathrm{meq} / \mathrm{g}$. Obtained anion exchanger has a low exchange capacity: $2.2-2.5 \mathrm{meq} / \mathrm{g}$, which is apparently due to the fact, that the amino group is located between the two benzene rings of DPA, and the presence of furfural affects not only transverse, but also in the main chain, significantly reducing the mobility of ionogenic groups.

However, due to the presence of aromatic nuclei and furfural heterocycle in the structure, obtained anion exchanger was resistant to thermal stresses and has high mechanical strength [10]. Research will be continued.

\section{Conclusion}

The results of polycondensation reaction based on diphenylamine and furfural obtained a new $96 \%$ mechanical stable anion exchanger using by DMF as a solvent. The temperature of the polycondensation reaction of DPA with furfural was taken at $100^{\circ} \mathrm{C}$, while the reaction is uniform, and the synthesized anion exchange resin has improved properties. The catalyst used was a Lewis catalyst with a concentration of $5-7 \%$ by weight of furfural. The reaction proceeds quite easily and evenly, which leads to the production of anion exchanger with the desired properties. The $\mathrm{ZnCl}_{2}$ catalyst with the participation of furfural formed a strong polarized active donor-acceptor complex and due to this $\pi$-complex, reaction of polycondensation proceeds in the mild mixture fairly easy. Thus, a method for producing a weakly basic anion-exchange polymer was developed in detail and its basic properties were investigated.

\section{Acknowledgments}

This work was carried out within the framework of the project of the Republic of Uzbekistan PZ-20170927346 Development of technology of ion-exchange polymers of polycondensation type for wastewater treatment.

\section{References}

1. S.M. Turabdzhanov, B.Sh. Kedelbaev, P.I.Kushnazarov, F.M.Badritdinova, T.V. Ponamaryova, L.S.Rakhimova, News. Nat.Acad.Sci.Rep.Kazakh., 2, 434 (2019)

2. C. Poole, Encyclopedia of Separation Science (Academic Press, 2000)

3. S. C. Moldoveanu, V. David, Selection of the HPLC Method in Chemical Analysis (Elsevier, 2017)

4. N. B. Mukhtarova, et.al., Con. Mod. Educ, 266-271, 2020

5. R. V. Law, D.C. Sherrington, Studies in Physical and Theoretical Chemistry (Solid State NMR of Polymers Isao Ando, 1998) 
6. L. S. Rakhimova, Uni: Chem. Biol. 8, 26 (2016)

7. V. V. Korshak, V.A. Vasnev, Comp. Pol. Sci. Sup, 5, 1989

8. D. Charles, Ion Exchange (John Wiley \& Sons, New York, NY, 1995)

9. D. Konrad, Ion Exchangers (Walter de Gruyter \& Co., Berlin, Germany, 1991)

10. L. S. Rakhimov, J. Adv. Sci, 3, 2014 